\title{
Depression in Patients with Epilepsy in Nigeria: Phenomenology and Predictors
}

\author{
Temitope Ogundare ${ }^{1,2, \odot}$
}

\begin{abstract}
Address for correspondence Temitope Ogundare, MD, MPH FWACP, FMC, Boston University School of Medicine, Boston, MA 02118, United States (e-mail: ogundare@bu.edu).
\end{abstract}

\author{
Abstract \\ Keywords \\ - epilepsy \\ - major depressive \\ disorder \\ - Nigeria \\ - dysthymia \\ - depression
}

Objectives In this article, we aimed to determine the correlates of depression among patients with epilepsy in Neuropsychiatric Hospital, Aro, Abeokuta, Nigeria.

Methods 270 patients with epilepsy attending the outpatient clinic of the hospital were recruited and assessed using sociodemographic questionnaire, MINI-Plus, and BDI-II.

Results The mean (standard deviation [SD]) age of the respondents was 32 (9.9) years, $45.6 \%$ were females, and $38.5 \%$ were married. Thirty-two (11.9\%) patients had a diagnosis of major depressive disorder (MDD) and 13 (4.8\%) had a diagnosis of dysthymia. The most common depressive symptoms were loss of pleasure (84.4\%), crying (84.4\%), self-dislike (81.3\%), and loss of energy, tiredness/fatigue, indecisiveness and punishment feelings (78.1\% each). Vegetative symptoms such as changes in appetite and sleep and loss of interest in sex were the least common depressive symptoms. In the logistic regression, seizure frequency was the single predictor of MDD and dysthymia. Patients who had at least one seizure per week were five times more likely to develop MDD ( $O R=5.1, p=0.014)$ and 16 times likely to have dysthymia $(O R=16.0$, $p=0.0007)$. Patients who had at least one seizure per month were 3 times more likely to develop MDD (OR = 3.3, $p=0.029)$.

Conclusion Seizure frequency is an independent predictor of depression among patients with epilepsy. Patients with poor seizure control are at higher risk of developing depression and should be routinely screened for depression.

\section{Introduction}

Globally, about 50 million people suffer from epilepsy, with the majority living in developing countries and receiving little or no treatment. ${ }^{1}$ Epilepsy is associated with a lot of physical, social, and psychological comorbidities including a high risk for suicide. ${ }^{2,3}$ Depression is the most common psychiatric comorbidity in patient with epilepsy. ${ }^{4,5}$ About a third of patients with epilepsy have comorbid major depressive disorder (MDD), ${ }^{6}$ and a still much larger proportion experience other forms of depression such as dysthymia, minor depression, and other depressive symptoms that do not meet the diagnostic criteria for mood disorders (termed subsyndromic mood disorders) ${ }^{7,8}$ However, depression is still largely underrecognized and treated among this population, leading to poor treatment outcomes and quality of life. ${ }^{9}$ Depression in patients with epilepsy has been associated with work absenteeism, increased health care system utilization and direct medical cost, and a poorer quality of life. ${ }^{10-12}$ published online April 1, 2021
DOI https://doi.org/ $10.1055 / \mathrm{s}-0041-1726163$ ISSN 2213-6320.
(C) 2021. Indian Epilepsy Society.

This is an open access article published by Thieme under the terms of the Creative Commons Attribution-NonDerivative-NonCommercial-License, permitting copying and reproduction so long as the original work is given appropriate credit. Contents may not be used for commercial purposes, or adapted, remixed, transformed or built upon. (https://creativecommons.org/licenses/by-nc-nd/4.0/) Thieme Medical and Scientific Publishers Pvt. Ltd., A-12, 2nd Floor, Sector 2, Noida-201301 UP, India 
This makes the recognition and treatment of depression in patients with epilepsy paramount. In Nigeria, as in other parts of Sub-Saharan Africa, depression in patients with epilepsy goes largely undetected and untreated. This study aims to determine the correlates (sociodemographic and clinical) of depression among patients with epilepsy attending an outpatient clinic in a tertiary hospital in Nigeria.

\section{Methods}

The study was conducted among patients with Epilepsy attending the outpatient clinic of the Neuropsychiatric Hospital, Aro, Abeokuta, Nigeria. The study is part of a larger study and the first part of the study has been published elsewhere. ${ }^{13}$ The inclusion criteria included patients with a clinical diagnosis of epilepsy, aged between 18 and 64 years; comorbid chronic medical and/or psychiatric illnesses, comorbid alcohol and substance use disorder, and a diagnosis of intellectual disability were exclusion criteria.

\section{Study Instruments}

Sociodemographic questionnaire: This was designed to gather data on participants' sociodemographic and clinical variables such as age, gender, age of onset of seizures, types and number of medications, duration of illness, etc.

Mini international neuropsychiatric interview (MINI Plus): Developed by Sheehan and colleagues in 1998 and found to have high validity and reliability scores or kappa values for all diagnoses above 0.70 ( $70 \%$ being above 0.90 ) when compared with the structured clinical interview for the DSM-IV patient version and the composite international diagnostic interview (CIDI). ${ }^{14}$ The depression disorder module of the MINI Plus was used in this study.

Beck's depression interview 2nd edition (BDI-II): A revised version of the 21-item Beck depression inventory (BDI), suitable for use in adults and adolescents, was altered to correspond to DSM-IV criteria for major depressive disorder and improve the content-validity.${ }^{15}$ Each item is scored on a scale value of 0 to 3 . Higher total scores indicate more severe depressive symptoms. The standardized cutoffs used differ from the original: 0 to 13 = minimal depression; 14 to 19 = mild depression; 20 to 28 = moderate depression; 29 to 63 = severe depression. Reported psychometric properties include sensitivity and specificity of $81 \%$ and $92 \%$, respectively, test-retest reliability of 0.93 , and internal consistency (Cronbach's $\alpha$ ) of $0.92 .{ }^{16}$

\section{Data Collection}

On each clinic day, case notes of patients were screened and those meeting the inclusion criteria identified and recruited after duly explaining the purpose of the research, explicitly stating the voluntary nature of participation and that no disadvantage will be conferred by deciding not to participate. Following a signed informed consent, the questionnaires were administered, while they waited to be seen by a doctor. To avoid sampling a patient twice, the case notes were marked with pencils and serial numbers were assigned to each participant to ensure confidentiality. Seizure frequency in the past month was defined as very frequent if seizures occurred daily or $>1$ /week; frequent if seizures occurred $1 /$ week or $>1$ /month; occasional if seizures occur $1 /$ month; and none if no seizures in the past month.

\section{Data Analysis}

The data was analyzed using the Statistical Package for Social Sciences (SPSS) version 21. Continuous variables such as age, duration of illness, duration of treatment, etc., were converted into categorical variables. Chi-square test (with Fischer's exact tests used when appropriate) was used to test the association between categorical variables and MDD. Next, a multiple logistic regression analysis was performed to determine the independent predictors of MDD and dysthymia. The level of statistical significance was set at $p$ value $<0.05$ at $95 \%$ confidence interval for all statistical tests.

\section{Results}

Of the 270 participants, 123 (45.6\%) were females, 104 (38.5\%) were married, 39 (14.4\%) were unemployed, with a mean age of 32 years (standard deviation $[S D]=9.9$ years); 133 (49.3\%) developed epilepsy at less than 18 years; 151 (55.9\%) had over 10 years of illness duration; 159 (58.9\%) had no seizures in the past month; $64.4 \%(n=174)$ had bilateral tonic clonic seizures, $12.6 \%(n=34)$ had focal with impaired awareness; $44.1 \%(N=119)$ were on carbamazepine, $89.6 \%(n=242)$ were on monotherapy; the mean duration of treatment was $6.1(\mathrm{SD}=6.5)$ years with $80.7 \%$ ( $n=218$ ) receiving treatment for less than 10 years. The prevalence of MDD was $11.9 \%(n=32)$, while that of dysthymia was $4.8 \%(n=13)$.

There was an association (- Table 1 ) between younger age $\left(\chi^{2}=11.808, \mathrm{df}=2, p=0.002\right)$; being single $\left(\chi^{2}=9.787\right.$, $\mathrm{df}=3, p=0.016)$; earning less than N5,000 $\left(\chi^{2}=12.077\right.$, $\mathrm{df}=4, p=0.012)$; younger age of onset $\left(\chi^{2}=3.890, \mathrm{df}=1\right.$, $p=0.049)$; having very frequent seizures $\left(\chi^{2}=19.668\right.$, $\mathrm{df}=4, p=0.001)$; having uncontrolled seizures $\left(\chi^{2}=5.83\right.$, $\mathrm{df}=1, p=0.012$ ) and MDD. There was no association between gender, type of seizures, types and number of automated external defibrillator (AED), duration of illness, duration of treatment, and MDD. In the bivariate analysis, only seizure frequency was associated with dysthymia $\left(\chi^{2}=16.64, \mathrm{df}=3, p\right.$ $=0.0026$ ); age, gender, seizure type, duration of illness, duration of treatment, employment and marital status, and type and number of AED were all not statistically significant.

Regarding the phenomenology of depression ( - Table 2 ), the most common depressive symptoms were loss of pleasure $(84.4 \%)$, crying $(84.4 \%)$, self-dislike $(81.3 \%)$, and loss of energy, tiredness/fatigue, indecisiveness and punishment feelings (78.1\% each). Vegetative symptoms such as changes in appetite and sleep and loss of interest in sex were the least common depressive symptoms. 
Table 1 Relationship between sociodemographic and clinical characteristics and current major depressive disorder ${ }^{\mathrm{b}}$

\begin{tabular}{|c|c|c|c|c|c|}
\hline \multirow[t]{2}{*}{ Variable } & \multicolumn{2}{|c|}{ Major depressive disorder } & \multirow[t]{2}{*}{$\chi^{2}$} & \multirow[t]{2}{*}{ df } & \multirow[t]{2}{*}{$p$-Value } \\
\hline & Yes (n/\%) & No $(n \mid \%)$ & & & \\
\hline \multicolumn{3}{|l|}{ Age } & 11.808 & 2 & 0.002 \\
\hline $15-24$ & $17(21.5)$ & $62(78.5)$ & & & \\
\hline $25-44$ & $15(9.3)$ & $146(90.7)$ & & & \\
\hline $45-64$ & $0(0.0)$ & $30(100.0)$ & & & \\
\hline \multicolumn{3}{|l|}{ Marital status } & 9.787 & 3 & 0.016 \\
\hline Single & $23(16.0)$ & $121(84.0)$ & & & \\
\hline Married & $5(4.8)$ & $99(95.2)$ & & & \\
\hline Separated & $3(16.7)$ & $15(83.3)$ & & & \\
\hline Widowed & $1(25.0)$ & $3(75.0)$ & & & \\
\hline \multicolumn{3}{|l|}{ Employment status } & 11.218 & 4 & 0.019 \\
\hline Paid employment & $11(6.9)$ & $149(93.1)$ & & & \\
\hline Unpaid & $7(22.6)$ & $24(77.4)$ & & & \\
\hline Retired & $0(0.0)$ & $2(100.0)$ & & & \\
\hline Unemployed & $6(15.4)$ & $33(84.6)$ & & & \\
\hline Student & $8(21.1)$ & $30(78.9)$ & & & \\
\hline \multicolumn{3}{|l|}{ Monthly income } & 12.077 & 4 & 0.012 \\
\hline Less than 5,000 & $23(18.7)$ & $100(81.3)$ & & & \\
\hline 5,000-9.999 & $3(8.1)$ & 34 (91.9) & & & \\
\hline $10,000-19,999$ & $5(10.9)$ & $41(89.1)$ & & & \\
\hline $20,000-49,999$ & $1(2.2)$ & $45(97.8)$ & & & \\
\hline$>50,000$ & $0(0.0)$ & $18(100.0)$ & & & \\
\hline \multicolumn{3}{|l|}{ Age of onset } & 3.890 & 1 & 0.049 \\
\hline$<18$ & $2115.8)$ & $112(84.2)$ & & & \\
\hline$>18$ & $11(8.0)$ & $126(92.0)$ & & & \\
\hline \multicolumn{3}{|l|}{ Seizure frequency past month } & 19.668 & 4 & 0.001 \\
\hline Daily or $>1 /$ week & $6(35.3)$ & $11(64.7)$ & & & \\
\hline $1 /$ week or $>1 /$ month & $1026.3)$ & $28(73.7)$ & & & \\
\hline 1/month & $6(10.7)$ & $50(89.3)$ & & & \\
\hline None & $10(6.3)$ & $149(93.7)$ & & & \\
\hline \multicolumn{3}{|l|}{ Seizure control $(n=228)$} & 5.830 & 1 & 0.012 \\
\hline Controlled (<1/year) & $2413.7)$ & $151(85.7)$ & & & \\
\hline Uncontrolled (> 1/year) & $1(1.9)$ & $52(98.1)$ & & & \\
\hline
\end{tabular}

${ }^{a}$ Fischer's exact values for cells with expected count less than 5 .

${ }^{b}$ Only statistically significant variables reported $(p<0.05)$.

In the multiple binary logistic regression analysis ( - Table 3), only seizure frequency in the past month emerged as the single independent predictor of MDD, with respondents with very frequent seizures in the past month having five times the risk of developing MDD when compared with those who had none ( $\mathrm{OR}=5.1, p=0.014,95 \% \mathrm{CI}=1.4-18.7)$, and those with frequent seizures in the past month having three times the risk of having
$\operatorname{MDD}(O R=3.3, p=0.029,95 \%$ CI = 1.1-9.5). Similarly, a multivariable logistic regression analysis of predictors of dysthymia ( - Table 4) showed seizure frequency in the past month as the only significant predictor of dysthymia. Patients who reported daily seizures or more than one seizure episode per week had 16 times odds of developing dysthymia compared with those with no seizures $(\mathrm{OR}=16.0, p=0.0007,95 \% \mathrm{CI}=3.2-79.3)$. 
Table 2 Frequency distribution of depressive symptoms in patients with epilepsy with MDD $(n=32)$

\begin{tabular}{|c|c|c|}
\hline BDI items & Depressive symptoms & $n(\%)$ \\
\hline 4 & Loss of pleasure & $27(84.4)$ \\
\hline 10 & Crying & $27(84.4)$ \\
\hline 7 & Self-dislike & $26(81.3)$ \\
\hline 6 & Punishment feelings & $25(78.1)$ \\
\hline 13 & Indecisiveness & $25(78.1)$ \\
\hline 15 & Loss of energy & $25(78.1)$ \\
\hline 20 & Tiredness/fatigue & $25(78.1)$ \\
\hline 2 & Pessimism & $24(75.0)$ \\
\hline 8 & Self-criticalness & $24(75.0)$ \\
\hline 12 & Loss of interest & $24(75.0)$ \\
\hline 14 & Worthlessness & $24(75.0)$ \\
\hline 1 & Sadness & 23 (71.9) \\
\hline 3 & Past failure & 23 (71.9) \\
\hline 5 & Guilty feelings & $23(71.9)$ \\
\hline 19 & Poor concentration & $21(65.6)$ \\
\hline 17 & Irritability & $19(59.4)$ \\
\hline 9 & Suicidal thoughts & $18(56.3)$ \\
\hline 11 & Agitation & $18(56.3)$ \\
\hline 21 & Loss of interest in sex & $17(53.1)$ \\
\hline 18 & Loss of appetite & $15(46.9)$ \\
\hline 16 & Too little sleep & $13(40.6)$ \\
\hline 18 & Increased appetite & $7(21.9)$ \\
\hline 16 & Excessive sleeping & $6(18.8)$ \\
\hline
\end{tabular}

Abbreviation: MDD, major depressive disorder.

\section{Discussion}

This study aimed at determining correlates of depression in patients with epilepsy attending an outpatient clinic in Nigeria. In this study, only seizure frequency in the past month emerged as an independent predictor of depression. Interictal depression is common in patients with epilepsy and often goes unrecognized. ${ }^{17}$ When researchers use a screening instrument such as BDI-II, ${ }^{18,19}$ the reported prevalence of MDD in patients with epilepsy is often higher than when a diagnostic instrument is used to make a diagnosis of MDD in patients with epilepsy. ${ }^{20-22}$ Regardless of the methodology, the prevalence of MDD in patients with epilepsy is higher than the prevalence in the general population. ${ }^{23}$ Apart from MDD, patients with epilepsy also have other forms of mood disorders such as dysthymia, and clusters of symptoms that do not meet the diagnostic criteria for a depressive disorder; these have been called "subsyndromic" mood disorders. ${ }^{24}$ The prevalence of dysthymia reported by participants in this study is lower than those reported in other studies; ${ }^{5-27}$ differences in methodology, study setting, and patient characteristics could account for this difference. In this study, majority of the participants had generalized tonic clonic seizures, were on one AED, and had controlled seizures; this may account for the low rates of dysthymia. Patients with refractory seizures and temporal lobe epilepsy are more likely to have higher rates of dysthymia-like depressive symptoms. ${ }^{8}$

There is a high comorbidity between depression and epilepsy and many studies have posited a bidirectional link between the two conditions. ${ }^{28-30}$ Probable underlying mechanisms that have been postulated as causes of depression in patients with epilepsy include the following: abnormal activities of GABA, glutamate, serotonin, noradrenaline and dopamine in the central nervous system; decreased binding of serotonin to 5HT1a receptors in the dorsal raphe nucleus, thalamus and cingulate gyrus; HPA axis dysfunction; and atrophy of frontal and temporal lobes. ${ }^{28}$ Depression can also cause seizures by causing sleep deprivation. ${ }^{31}$ This makes the evaluation and treatment of depression an important part of the treatment of patients with epilepsy, as depression in people with epilepsy is often underrecognized and untreated, with an attendant negative effect on medication adherence, seizure control, and an increased risk of suicide. ${ }^{17,32,33}$

With regard to semiology, the most common depressive symptoms reported by our sample include crying, loss of pleasure, self-dislike, loss of energy, tiredness/fatigue, indecisiveness, and punishment feelings. Vegetative symptoms such as changes in appetite and sleep and loss of interest in sex were the least common depressive symptoms. This is consistent with the literature regarding manifestations of depression among patients with epilepsy. ${ }^{7,8}$

In this study, seizure frequency emerged as the single independent predictor of MDD in keeping with other studies. ${ }^{21,34-36}$ The study found that those who had at least one seizure per week were five times more likely to develop MDD and those who have at least one seizure in a month were three times more likely to develop MDD when compared with those who had good seizure control. This makes it important for clinicians to optimize treatment regimen of patients with epilepsy to achieve good seizure control. In addition, patients who have not gained seizure control are at higher risk of developing MDD and therefore should be routinely screened for MDD and treated appropriately. Selective serotonin reuptake inhibitors (SSRIs) and other newer antidepressants have been proven to be effective in treating comorbid depression in patients with epilepsy and this can be commenced as soon as a diagnosis of depression is made. ${ }^{30,37}$ In addition to pharmacotherapy, there is increasing evidence of the benefit of psychological therapies such as cognitive behavioral therapy delivered in person or online for patients with epilepsy. ${ }^{31,38}$

Other clinical variables such as type of epilepsy, duration of epilepsy, and type and number of antiepileptic medications were not found to be associated with major depression or dysthymia in the final regression analysis. This finding is similar to other studies ${ }^{39-41}$ but different from others. ${ }^{42,43}$ It is possible that the relationship between these clinical variables is mediated or moderated by seizure control, ${ }^{36,44}$ and as majority of the participants had good seizure control, these clinical variables did not attain statistical significance. There could be also be methodological differences between these studies and this study-differences in participant characteristics according for the disparity. 
Table 3 Logistic regression analysis of the sociodemographic and clinical correlates of MDD

\begin{tabular}{|c|c|c|c|c|c|c|}
\hline \multirow[t]{2}{*}{ Variable } & \multirow[t]{2}{*}{ B } & \multirow[t]{2}{*}{ Wald } & \multirow[t]{2}{*}{$p$ value } & \multirow[t]{2}{*}{ OR } & $95 \% \mathrm{Cl}$ & \multirow[t]{2}{*}{ Upper } \\
\hline & & & & & Lower & \\
\hline \multicolumn{7}{|l|}{ Marital status } \\
\hline Married & -0.528 & 0.750 & 0.387 & 0.590 & 0.179 & 1.947 \\
\hline Separated & 0.041 & 0.003 & 0.957 & 1.042 & 0.236 & 4.593 \\
\hline Widowed & 1.273 & 0.833 & 0.361 & 3.570 & 0.232 & 54.877 \\
\hline Single & Reference & & & & & \\
\hline \multicolumn{7}{|l|}{ Seizure frequency past month } \\
\hline Very frequent (daily or > 1/week) & 1.630 & 6.064 & 0.014 & 5.104 & 1.395 & 18.677 \\
\hline Frequent (1/week or $>1 /$ month) & 1.184 & 4.764 & 0.029 & 3.266 & 1.128 & 9.456 \\
\hline Occasional (1/month) & 0.283 & 0.229 & 0.632 & 1.327 & 0.417 & 4.221 \\
\hline None & Reference & & & & & \\
\hline \multicolumn{7}{|l|}{ Age of onset (years) } \\
\hline$<18$ years & 0.155 & 0.114 & 0.736 & 1.167 & 0.475 & 2.870 \\
\hline$>18$ years & Reference & & & & & \\
\hline \multicolumn{7}{|l|}{ Seizure control } \\
\hline Uncontrolled seizure & 1.579 & 2.073 & 0.150 & 4.849 & 0.565 & 41.584 \\
\hline Controlled seizure & Reference & & & & & \\
\hline \multicolumn{7}{|l|}{ Employment status } \\
\hline Unpaid employment & 0.777 & 1.509 & 0.219 & 2.176 & 0.630 & 7.520 \\
\hline Unemployed & -0.140 & 0.054 & 0.816 & 0.869 & 0.265 & 2.844 \\
\hline Retired/Student & 0.451 & 0.540 & 0.462 & 1.570 & 0.471 & 5.232 \\
\hline Paid employment & Reference & & & & & \\
\hline \multicolumn{7}{|l|}{ Monthly income } \\
\hline$<20,000$ & 1.657 & 2.333 & 0.127 & 5.243 & 0.626 & 43.942 \\
\hline$>20,000$ & Reference & & & & & \\
\hline
\end{tabular}

Abbreviation: MDD, major depressive disorder.

Table 4 Stepwise logistic regression analysis of independent predictors of dysthymia in patients with epilepsy

\begin{tabular}{|l|l|l|l|l|}
\hline Variable & B & OR & \multicolumn{1}{l|}{$\boldsymbol{p}$ value } & Cl (lower, upper) \\
\hline Seizure frequency in past month & 2.8 & 16.0 & $\mathbf{0 . 0 0 0 7}$ & $3.2,79.3$ \\
\hline Daily or $>1 /$ week & 1.1 & & 0.25 & $0.5,17.9$ \\
\hline $1 /$ week or $>1 /$ month & 1.4 & 2.9 & 0.08 & $0.9,18.5$ \\
\hline $1 /$ month or $>1 /$ year & Reference & 4.0 & & \\
\hline None & Number of AED & \\
\hline Summary of variables removed in each step & Duration of treatment \\
\hline Step 1 & Seizure control \\
\hline Step 2 & Type of AED & \\
\hline Step 3 & Age of onset \\
\hline Step 4 & Duration of illness \\
\hline Step 5 & Employment status \\
\hline Step 6 & Marital status \\
\hline Step 7 & Seizure type \\
\hline Step 8 & Gender \\
\hline Step 9 & Monthly income \\
\hline Step 10 &
\end{tabular}

Abbreviation: AED, automated external defibrillator. 
The cross-sectional nature of the study design, and the fact that it is a single-site study limits the generalization of the study findings to other populations. However, it does contribute to the literature coming out of Nigeria and Sub-Saharan Africa on the prevalence and correlates of depression among patients with epilepsy. The small sample size also led to a wider confidence interval for some of the measures of association, especially for those with dysthymia. A much larger study with a much larger sample size is needed to increase the confidence in the magnitude of risk that seizure frequency poses to the development of dysthymia in patients with epilepsy. The study highlights the need for clinicians treating patients in these locations to be aware of comorbid depression and to routinely screen patients, especially high-risk patients-those with poor seizure control. It also lends urgency to the need for optimizing treatment for patients with epilepsy to achieve good seizure control.

\section{Ethical Approval}

The study was granted ethical approval from the Research and Ethical Committee of the Neuropsychiatric Hospital, Aro, Abeokuta, Ogun state, Nigeria.

\section{Conflict of Interest \\ None declared}

\section{Acknowledgments}

The author would like to appreciate the contributions of the following: Drs. Adebowale, Ogunwale, Adeniji, Nzeakah, Omotosho, and Okonkwo at various stages of the research.

\section{References}

1 Meinardi H, Scott RA, Reis R, Sander JWAS; ILAE Commission on the Developing World. The treatment gap in epilepsy: the current situation and ways forward. Epilepsia 2001;42(1):136-149

2 Kobau R, Cui W, Kadima N, et al. Tracking psychosocial health in adults with epilepsy-estimates from the 2010 National Health Interview Survey. Epilepsy Behav 2014;41:66-73

3 Verrotti A, Cicconetti A, Scorrano B, et al. Epilepsy and suicide: pathogenesis, risk factors, and prevention. Neuropsychiatr Dis Treat 2008;4(2):365-370

4 Bosak M, Dudek D, Siwek M. [Depression in patients with epilepsy]. Psychiatr Pol 2012;46(5):891-902

5 Kanner AM. Depression in epilepsy: prevalence, clinical semiology, pathogenic mechanisms, and treatment. Biol Psychiatry 2003;54(3):388-398

6 Rai D, Kerr MP, McManus S, Jordanova V, Lewis G, Brugha TS. Epilepsy and psychiatric comorbidity: a nationally representative population-based study. Epilepsia 2012;53(6):1095-1103

7 Kanner AM. Depression and epilepsy: a new perspective on two closely related disorders. Epilepsy Curr 2006;6(7):141-146

8 Miller JM, Kustra RP, Vuong A, Hammer AE, Messenheimer JA. Depressive symptoms in epilepsy: prevalence, impact, aetiology, biological correlates and effect of treatment with antiepileptic drugs. Drugs 2008;68(11):1493-1509

9 Hermann BP, Seidenberg M, Bell B. Psychiatric comorbidity in chronic epilepsy: identification, consequences, and treatment of major depression. Epilepsia 2000;41(6, Suppl 2) :S31-S41

10 Johnson EK, Jones JE, Seidenberg M, Hermann BP. The relative impact of anxiety, depression, and clinical seizure features on health-related quality of life in epilepsy. Epilepsia 2004; 45(5):544-550
11 Szaflarski JP, Szaflarski M. Seizure disorders, depression, and health-related quality of life. Epilepsy Behav 2004;5(1):50-57

12 Fiest KM, Dykeman J, Patten SB, et al. Depression in epilepsy: a systematic review and meta-analysis. Neurology 2013;80(6): 590-599

13 Ogundare T, Adebowale TO, Borba CP, Henderson DC. Correlates of depression and quality of life among patients with epilepsy in Nigeria. Epilepsy Res 2020;164:106344

14 Sheehan DV, Lecrubier Y, Sheehan KH, et al. The MiniInternational Neuropsychiatric Interview (M.I.N.I.): the development and validation of a structured diagnostic psychiatric interview for DSM-IV and ICD-10. J Clin Psychiatry 1998; 59(Suppl 20):22-33, quiz 34-57

15 Beck AT, Brown, GK, Steer, RA, Manual for the Beck Depression Inventory-II. San Antonio, TX: Psychological Corporation; 199638

16 Beck AT, Steer RA, Ball R, Ranieri W. Comparison of Beck depression inventories -IA and -II in psychiatric outpatients. J Pers Assess 1996;67(3):588-597

17 Kanner AM, Palac S. Depression in epilepsy: a common but often unrecognized comorbid malady. Epilepsy Behav 2000; 1(1):37-51

18 Fatoye F, Mosaku KS, Komolafe M, Adewuya AO. Interictal anxiety and depression symptoms in Nigerians with epilepsy: a controlled study. Epilepsy Behav 2006;9(2):312-316

19 Ogunrin OA, Obiabo YO. Depressive symptoms in patients with epilepsy: analysis of self-rating and physician's assessment. Neurol India 2010;58(4):565-570

20 Ayanda KA, Sulyman D. The predictors of psychiatric disorders among people living with epilepsy as seen in a Nigerian Tertiary Health Institution. Niger Med J 2016;57(1):24-30

21 Owolabi D, Owolabi L, Udofia O, Sale S. Depression in Clinically Diagnosed Patients with Epilepsy in Northwestern Nigeria (P4. 207) Neurology 2016;86(16)(Supple). Available at: http://n. neurology.org/content/86/16_Supplement/P4.207.short

22 Seshadri V, Thomas J, Murthy JMK, Raju CR. Prevalence of depression and its effect on quality of life in patients with epilepsy: a community based study and a Comprehensive Rural Epilepsy Study in South India (CRESSI). Neurol Asia 2004; 9(1):139

23 Chandrasekharan SC, Menon V, Wadwekar V, Nair PP. High frequency of depressive symptoms among adults with epilepsy: results from a hospital-based study. J Neurosci Rural Pract 2017;8(Suppl 1) :S13-S19

24 Kanner A, Wuu J, Barry J, Hermann B, Meador K, Gilliam F. Atypical depressive episodes in epilepsy: a study of their clinical characteristics and impact on quality of life Neurology 2004 Apr;62(7):3-153

25 Desai SD, Shukla G, Goyal V, et al. Study of DSM-IV Axis I psychiatric disorders in patients with refractory complex partial seizures using a short structured clinical interview. Epilep Behav 2010;19(3):301-305

26 Gonçalves EB, Cendes F. Depression in patients with refractory temporal lobe epilepsy. Arq Neuropsiquiatr 2011;69(5): 775-777

27 Bosak M, Dudek D, Siwek M, Szczudlik A. Subtypes of interictal depressive disorders according to ICD-10 in patients with epilepsy. Neurol Neurochir Pol 2015;49(2):90-94

28 Kanner AM. Depression in epilepsy: a neurobiologic perspective. Epilepsy Curr 2005;5(1):21-27

29 Kanner AM. Depression and epilepsy: a new perspective on two closely related disorders. Epilepsy Curr 2006;6(5):141-146

30 Borgmann M, Holtkamp M, Adli M, Behr J. [Depression and epilepsy: two clinical pictures with common causes?]. Nervenarzt 2016;87(7):724-730

31 Gnanavel S. Epilepsy and depression: a bidirectional relationship. J Neurosci Rural Pract 2017;8(Suppl 1) :S5-S6 
32 Ettinger AB, Good MB, Manjunath R. Edward Faught R, Bancroft $T$. The relationship of depression to antiepileptic drug adherence and quality of life in epilepsy. Epilepsy Behav 2014; 36(0):138-143

33 Cramer JA, Blum D, Reed M, Fanning K; Epilepsy Impact Project Group. The influence of comorbid depression on seizure severity. Epilepsia 2003;44(12):1578-1584

34 Thompson AW, Miller JW, Katon W, Chaytor N, Ciechanowski P. Sociodemographic and clinical factors associated with depression in epilepsy. Epilepsy Behav 2009;14(4):655-660

35 Fawale MB, Owolabi MO, Ogunniyi A. Effects of seizure severity and seizure freedom on the health-related quality of life of an African population of people with epilepsy. Epilepsy Behav 2014;32:9-14

36 Park SP, Song HS, Hwang YH, Lee HW, Suh CK, Kwon SH. Differential effects of seizure control and affective symptoms on quality of life in people with epilepsy. Epilepsy Behav 2010;18(4):455-459

37 Cardamone L, Salzberg MR, O’Brien TJ, Jones NC. Antidepressant therapy in epilepsy: can treating the comorbidities affect the underlying disorder? Br J Pharmacol 2013;168(7):1531-1554
38 Meyer B, Weiss M, Holtkamp M, et al. Protocol for the ENCODE trial: evaluating a novel online depression intervention for persons with epilepsy. BMC Psychiatry 2017;17(1):55

39 Lacey CJ, Salzberg MR, D'Souza WJ. What factors contribute to the risk of depression in epilepsy?-Tasmanian Epilepsy Register Mood Study (TERMS) Epilepsia 2016;57(3):516-522

40 Nubukpo P, Houinato D, Preux P-M, Avodé G, Clément J-P. [Anxiety and depression among the epileptics in general population in Benin (Western Africa)]. Encephale 2004;30(3): 214-219

41 Phabphal K, Sattawatcharawanich S, Sathirapunya P, Limapichart K. Anxiety and depression in Thai epileptic patients. J Med Assoc Thai 2007;90(10):2010-2015

42 Dias R, Bateman LM, Farias ST, et al. Depression in epilepsy is associated with lack of seizure control. Epilepsy Behav 2010; 19(3):445-447

43 Siarava E, Hyphantis T, Katsanos AH, Pelidou SH, Kyritsis AP, Markoula S. Depression and quality of life in patients with epilepsy in Northwest Greece. Seizure 2019;66:93-98

44 Kwon OY, Park SP. Depression and anxiety in people with epilepsy. J Clin Neurol 2014;10(3):175-188 